\title{
Height Partition Effect on Combined Mixed Convection and Surface Radiation in a Vented Rectangular Cavity
}

\author{
A. Bahlaoui ${ }^{1}$, A. Raji ${ }^{2}$, M. Hasnaoui ${ }^{3}$, C. Ouardi ${ }^{2}$, M. Naïmi ${ }^{2}$ and T. Makayssi ${ }^{2}$ \\ ${ }^{1}$ Sultan Moulay Slimane University, Polydisciplinary Faculty, Physics Department, Interdisciplinary Laboratory of \\ Research in Sciences and Technologies (LIRST), B. P. 523, Béni-Mellal 23000, Morocco \\ ${ }^{2}$ Sultan Moulay Slimane University, Faculty of Sciences and Technologies, Physics Department, Laboratory of Flows \\ and Transfers Modelling (LAMET), B. P. 523, Béni-Mellal 23000, Morocco \\ ${ }^{3}$ Cadi Ayyad University, Faculty of Sciences Semlalia, Physics Department, Laboratory of Fluid Mechanics and \\ Energetics (LMFE), B.P. 2390, Marrakech, Morocco
}

Email:abderaji@fstbm.ac.ma and abderaji@yahoo.fr

(Received February 17, 2009; accepted November 02, 2009)

\begin{abstract}
The present paper reports numerical results of mixed convection and surface radiation within a horizontal ventilated cavity heated from below and provided with an adiabatic thin partition on the heated surface. Air, a radiatively transparent medium, is considered to be the cooling fluid. The effect of the governing parameters, which are the Reynolds number, $200 \leq \mathrm{Re} \leq 5000$, the relative height of the baffle, $0 \leq \mathrm{H}_{\mathrm{b}} \leq 0.75$, and the emissivity of the walls, 0 $\leq \varepsilon \leq 1$, on the fluid flow and heat transfer characteristics is studied in detail. The maximum and mean temperatures, the ratio, $\mathrm{Q}_{\mathrm{E}} / \mathrm{Q}_{\mathrm{L}}$, of the heat quantities leaving the cavity through the exit, $\mathrm{Q}_{\mathrm{E}}$, and through the left vertical cold side, $\mathrm{Q}_{\mathrm{L}}$, are also presented versus the above controlling parameters.
\end{abstract}

Keywords: Mixed convection; surface radiation; numerical study; ventilated cavity; adiabatic partition

\section{NOMENCLATURE}

$A \quad$ aspect ratio of the cavity, $\mathrm{L}^{\prime} / \mathrm{H}^{\prime}$

$B$ relative height of the openings, $\mathrm{h}^{\prime} / \mathrm{H}^{\prime}$

$F_{i j} \quad$ view factor from $\mathrm{S}_{\mathrm{i}}$ surface to $\mathrm{S}_{\mathrm{i}}$

$g \quad$ acceleration due to gravity $\left(\mathrm{m} / \mathrm{s}^{2}\right)$

$h^{\prime} \quad$ height of the openings (m)

$\mathrm{H}^{\prime} \quad$ height of the cavity $(\mathrm{m})$

$H_{b} \quad$ relative height of the baffle, $\mathrm{H}_{\mathrm{b}}^{\prime} / \mathrm{H}^{\prime}$

$I_{i} \quad$ dimensionless irradiation, $\mathrm{I}_{\mathrm{i}}^{\prime} / \sigma \mathrm{T}_{\mathrm{C}}^{\prime 4}$

$J_{i} \quad$ dimensionless radiosity, $\mathrm{J}_{\mathrm{i}}^{\prime} / \sigma \mathrm{T}_{\mathrm{C}}^{\prime 4}$

$\ell^{\prime} \quad$ width of the partition (m)

$\mathrm{L}^{\prime} \quad$ length of the cavity (m)

$L_{b} \quad$ dimensionless $\mathrm{x}$-direction distance of the baffle from the inlet, $\mathrm{L}_{\mathrm{b}}^{\prime} / \mathrm{H}^{\prime}$

$\mathrm{Nr}$ convection-radiation interaction parameter, $\sigma \mathrm{T}_{\mathrm{C}}^{\prime 4} / \mathrm{q}^{\prime}$

$\mathrm{Nu}$ average Nusselt number

Pr Prandtl number, $v / \alpha$

$q^{\prime} \quad$ imposed wall heat flux $\left(\mathrm{W} / \mathrm{m}^{2}\right)$

$Q_{r} \quad$ dimensionless radiative heat flux, $\mathrm{Q}_{\mathrm{r}}^{\prime} / \sigma \mathrm{T}_{\mathrm{C}}^{\prime 4}$

$R a \quad$ Rayleigh number, g $\beta \mathrm{q}^{\prime} \mathrm{H}^{\prime 4} / \alpha \mathrm{v} \lambda$
Re Reynolds number, $\mathrm{u}_{\mathrm{o}}^{\prime} \mathrm{H}^{\prime} / \mathrm{v}$

$R i \quad$ Richardson number, $\mathrm{Ra} / \mathrm{Re}^{2} \mathrm{Pr}$

$t$ dimensionless time, $\mathrm{t}^{\prime} \mathrm{u}_{\mathrm{o}}^{\prime} / \mathrm{H}^{\prime}$

$T$ dimensionless fluid temperature, $\lambda\left(\mathrm{T}^{\prime}-\mathrm{T}_{\mathrm{C}}^{\prime}\right) / \mathrm{q}^{\prime} \mathrm{H}^{\prime}$

$T^{\prime} \quad$ dimensional fluid temperature $(\mathrm{K})$

$\bar{T} \quad$ dimensionless mean temperature

$T_{\max }$ dimensionless maximum temperature

$T_{C}^{\prime} \quad$ common temperature of the left vertical cold wall and imposed flow (K)

$T_{o} \quad$ dimensionless reference temperature, $\lambda \mathrm{T}_{\mathrm{C}}^{\prime} / \mathrm{q}^{\prime} \mathrm{H}^{\prime}$

$u_{o}^{\prime} \quad$ velocity of the imposed flow $(\mathrm{m} / \mathrm{s})$

$(u, v)$ dimensionless horizontal and vertical velocities, $\left(\mathrm{u}^{\prime}, \mathrm{v}^{\prime}\right) / \mathrm{u}_{\mathrm{o}}^{\prime}$

$(x, y)$ dimensionless coordinates, $\left(\mathrm{x}^{\prime}, \mathrm{y}^{\prime}\right) / \mathrm{H}^{\prime}$

Greek symbols

$\alpha \quad$ thermal diffusivity of fluid $\left(\mathrm{m}^{2} / \mathrm{s}\right)$

$\beta \quad$ thermal expansion coefficient of fluid $(1 / \mathrm{K})$

$\Delta t \quad$ dimensionless time step 
$\varepsilon \quad$ walls emissivity

$\lambda$ thermal conductivity of fluid (W/(K.m))

$v \quad$ kinematic viscosity of fluid $\left(\mathrm{m}^{2} / \mathrm{s}\right)$

$\Omega \quad$ dimensionless vorticity, $\Omega^{\prime} \mathrm{H}^{\prime} / \mathrm{u}_{\mathrm{o}}$

$\Psi \quad$ dimensionless stream function, $\Psi^{\prime} / \mathrm{u}_{\mathrm{o}}^{\prime} \mathrm{H}^{\prime}$

$\sigma \quad$ Stéfan-Boltzman constant,

$$
5.6697 \times 10^{-8} \mathrm{~W} / \mathrm{m}^{2} \mathrm{~K}^{4}
$$

\section{Subscripts}

C cold temperature

\section{INTRODUCTION}

Mixed convection heat transfer in ventilated systems continues to be a fertile area of research, due to the interest of the phenomenon in many technological processes, such as the design of solar collectors, thermal design of buildings, air conditioning and recently the cooling of electronic circuit boards. In ventilated enclosures, the interaction between the external forced stream and the buoyancy driven flow induced by buoyancy forces could lead to complex flow structures. In the literature, numerous analytical, numerical and experimental studies dealing with mixed convection in ventilated geometries have been reported without radiation effect. The effect of the latter can be neglected in the case of configurations with nonemissive or weakly emissive boundaries which is not the case in general since the contribution of radiation to the overall heat transfer could be significant. In the absence of radiation, Papanicolaou and Jaluria (1990, 1993) studied numerically the mixed convection transport in a rectangular enclosure provided with an isolated heat source generating a uniform heat flux. Their results showed that the average Nusselt number increases by increasing the solid wall thermal conductivity. Laminar mixed convection in a " $\mathrm{T}$ " form cavity with heated rectangular blocks submitted to a vertical jet of fresh air from below was studied numerically by Najam et al. (2004). Their results show the validity of multiple solutions on which the resulting heat transfer depends, and useful correlations were proposed. Mixed convection in a square enclosure provided with a partially dividing partition was studied numerically by $\mathrm{Hsu}$ et al. (1997). Results of the simulations indicate that the heat dissipated from the source is maximum when the outflow opening is located at the lower part of the vertical wall. A better heat removal was also possible when the heat source was located as close as possible to the cold stream inlet opening. The case of transient mixed convection in a square enclosure with a partially dividing partition was also studied by How and Hsu (1998). Results of the study show that, generally, either higher values of Re or lower values of $\mathrm{Gr} / \mathrm{Re}^{2}$ delay the achievement of the steady state solutions. A numerical study was conducted by Mousavi and Hooman (2006) on mixed convective heat transfer in a rectangular channel with segmented baffles that are well arranged on both the top and bottom walls of the channel. The authors found that the Reynolds and the Prandtl numbers affect the precise location of the periodically fully developed region similar to the case of the smooth channel. Laminar mixed convection in a two-dimensional enclosure with assisting and opposing flows was studied numerically by Raji and Hasnaoui in the case of a cavity uniformly

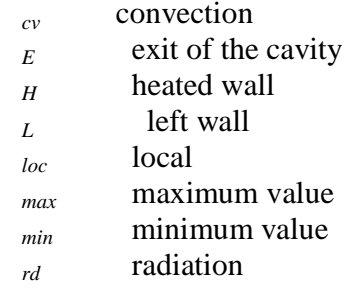

\section{Superscripts}

\section{dimensional variable}

heated from one side wall Raji and Hasnaoui (1998a, $1998 \mathrm{~b}$ ) or with prescribed equal heat fluxes on the top horizontal wall and the vertical left one Raji and Hasnaoui (2000). The obtained results show that the Re-Ra plane can be divided in regions corresponding to the dominance of the forced convection or to the mixed convection regime where the heat transfer is maximum (maximum thermal interaction between forced and natural convection) and the limits between both regimes were correlated in terms of Re versus Ra. Manca et al. (2003) studied numerically the effect of the heated wall position on mixed convection in a partially open cavity. The results show that the opposing forced flow configuration was found to achieve the highest thermal performance in terms of both maximum temperature and average Nusselt number. Laminar mixed convection in a two-dimensional enclosure, differentially heated, was studied numerically by Singh and Sharif (2003). They reported that maximum cooling effectiveness is achieved if the inlet and the outlet openings are respectively located near the bottom of the cold wall and the top of the hot wall. Laminar doublediffusive mixed convection in a two-dimensional ventilated enclosure was numerically investigated by Deng et al. (2004). Combined effects of the Grashof number, the Reynolds number, the buoyancy ratio and the ventilation mode on the indoor air environment were examined. A numerical study of laminar mixed convection in a shallow enclosure with a series of block-like heat generating components with floor admission openings and ceiling extraction openings was conducted by Bhoite et al. (2005). It was reported that the effect of buoyancy becomes insignificant for Re > 600. Combined free and forced convections from a flush-mounted uniform heat source on the bottom of a horizontal rectangular enclosure with two exit ports, located at the top of the vertical walls, was recently studied numerically by Saha et al. (2006). Useful correlations are proposed for the Nusselt number versus Reynolds and Richardson numbers. In the case of ventilated cavities, the numerical study, conducted by Raji and Hasnaoui (2001) on combined mixed convection and radiation, showed that the contribution of radiation could be important even though the cooling fluid is transparent to radiation. Heat transfer by mixed convection in the presence of radiation, in spite of its obvious interest, has not yet received much importance in the literature. The neglected effect of thermal radiation is mainly justified by the fact that the heat transfer is especially ensured by mixed or forced convection. However, moderate temperature differences give rise to significant radiation effects and the fact of neglecting their contribution becomes unrealistic. On the basis of the literature review, it appears that no work was reported on coupled mixed convection and 
radiation in ventilated rectangular partitioned enclosures. Thereafter, due to the practical interest of this problem in a wide variety of engineering applications of passive cooling of electronic equipment such as compact power supplies, portable computers and telecommunications enclosures, the subject needs further effort to improve the knowledge in this field. Hence, the present study consists in studying numerically a mixed convection problem in a ventilated partitioned cavity heated from below with a constant heat flux. In this analysis, the forced flow enters the cavity through an opening located in lower part of the cold vertical left wall and leaves it from an opening located in the upper part of the opposite adiabatic wall. The main objective of the present study consists of examining the effect of the Reynolds number, Re, the relative height of the partition, $\mathrm{H}_{b}$, and the emissivity of the walls, $\varepsilon$, on flow and thermal fields and heat amount dissipated through the exit and the vertical cold wall. Variations, versus the main controlling parameters, of maximum and mean temperatures are also explored.

\section{Problem Formulation}

The configuration under study, together with the system of coordinates is depicted in Fig. 1. It consists of a ventilated rectangular cavity having an aspect ratio $\mathrm{A}=$ 2. The bottom wall is uniformly heated with a constant heat flux and provided with a vertical adiabatic baffle of relative width $e=\ell^{\prime} / H^{\prime}=0.025$. The upper horizontal and right vertical walls are considered insulated, while the left side of the cavity is cooled with a constant temperature. The system is submitted to an imposed flow of ambient air through an opening located on the lower part of left vertical wall. The forced flow leaves the cavity through an outflow opening placed on the upper part of the right vertical wall. The inner surfaces, in contact with the fluid, are assumed to be gray, diffuse emitters and reflectors of radiation with identical emissivities. The third dimension of the cavity (direction perpendicular to the plane of the diagram) is assumed to be large enough so that the fluid flow can be considered two-dimensional. The fluid properties are evaluated at a cold temperature and the airflow is assumed to be laminar, incompressible and obeying the Boussinesq approximation. Under these assumptions, the dimensionless governing equations, written in terms of the vorticity and stream function formulation, are as follows:

$$
\begin{aligned}
& \frac{d \Omega}{d t}=\frac{1}{\operatorname{Re}}\left[\frac{\partial^{2} \Omega}{\partial x^{2}}+\frac{\partial^{2} \Omega}{\partial y^{2}}\right]+\frac{\operatorname{Ra}}{\operatorname{Re}^{2} \operatorname{Pr}} \frac{\partial T}{\partial x} \\
& \frac{d T}{d t}=\frac{1}{\operatorname{Re} \operatorname{Pr}}\left[\frac{\partial^{2} T}{\partial x^{2}}+\frac{\partial^{2} T}{\partial y^{2}}\right] \\
& \frac{\partial^{2} \Psi}{\partial x^{2}}+\frac{\partial^{2} \Psi}{\partial y^{2}}=-\Omega
\end{aligned}
$$

The stream function and the vorticity are related to the velocity components by the following expressions:

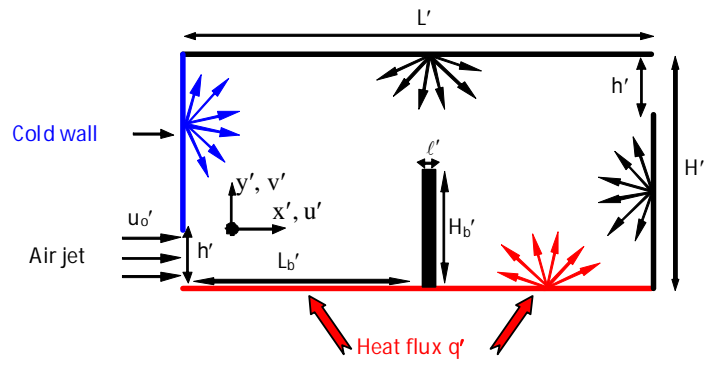

Fig. 1. Schematic of the studied configuration.

$$
u=\frac{\partial \Psi}{\partial y}, v=-\frac{\partial \Psi}{\partial x} \text { and } \Omega=\frac{\partial v}{\partial x}-\frac{\partial u}{\partial y}
$$

\subsection{Boundary Conditions}

The boundary conditions, associated with the problem are as follows:

- on the rigid walls : $\mathrm{u}=\mathrm{v}=0$

- at the inlet of the cavity: $\mathrm{T}=\mathrm{v}=\Omega=0, \mathrm{u}=1$ and $\Psi$ $=\mathrm{y}$

- on the left vertical cold wall : $\mathrm{T}=0$

- on the lower horizontal heated wall :

$$
-\frac{\partial T}{\partial y}+N_{r} Q_{r}=1
$$

- on the adiabatic walls : $-\frac{\partial T}{\partial n}+N_{r} Q_{r}=0$

$" n "$ being the normal direction to the considered adiabatic wall.

For this problem, the boundary conditions are unknown at the outflow opening. Values of $\mathrm{u}, \mathrm{v}, \mathrm{T}, \Psi$ and $\Omega$ are obtained at each time step by means of an extrapolation technique (Bahlaoui et al., 2004, 2005). This technique is based on zero second derivatives for all the abovementioned variables at the exit of the cavity.

\subsection{Radiation Equations}

By using the net-radiation method for an enclosure, it is possible to derive an expression for the relationship between the localized heat flux due to radiative heat transfer and the surface temperature. The walls of the cavity and the partition are divided into $\mathrm{N}=289$ elementary segments for the grid retained $(81 \times 41)$. Each segment is sufficiently short to be considered isothermal. The view factors between the isothermal elementary surfaces were determined by the Hottel's (1967) crossed string method. However, by its presence, the partition can shade the views between some pairs of surfaces; which required the development of an appropriate numerical code, including the shadow effects, to compute the view factors. It is to precise that the summation rules were checked to be sure that the view factors summation equals unity for each surface. The calculation of the radiative heat exchange between the cavity and its surrounding (through the inlet and the exit) is based on the radiosity method. The inner surfaces of the enclosure are assumed to be opaque, diffuse and gray. The non-dimensional radiosity equation for the $i^{\text {th }}$ element of the enclosure, in the case 
of a radiatively non-participating medium, may be written as:

$$
J_{i}=\varepsilon_{i}\left(\frac{T_{i}}{T_{o}}+1\right)^{4}+\left(1-\varepsilon_{i}\right) \sum_{j=l}^{N} F_{i j} J_{j}
$$

The dimensionless net radiative heat flux leaving an element of surface $S_{i}$ is evaluated by:

$$
Q_{r}=J_{i}-I_{i}=\varepsilon_{i}\left[\left(\frac{T_{i}}{T_{o}}+1\right)^{4}-\sum_{j=1}^{N} F_{i j} J_{j}\right]
$$

\subsection{Heat Transfer}

The average Nusselt numbers, characterizing the contributions of mixed convection and thermal radiation through the heated wall, are respectively defined as:

$$
\begin{aligned}
& N u_{c v}=-\left.\frac{1}{A} \int_{0}^{A} \frac{1}{T}\left(\frac{\partial T}{\partial y}\right)\right|_{y=0} d x \\
& N u_{r d}=\left.\frac{1}{A} \int_{0}^{A} \frac{1}{T}\left(N_{r} Q_{r}\right)\right|_{y=0} d x
\end{aligned}
$$

The total Nusselt number, $\mathrm{Nu}$, is evaluated as being the sum of the corresponding convective and radiative Nusselt numbers, i.e. $\mathrm{Nu}=\mathrm{Nu}_{\mathrm{cv}}+\mathrm{Nu}_{\mathrm{rd}}$.

The total heat quantities leaving the cavity through the left side and the exit are respectively given by:

$$
\begin{aligned}
& Q_{L}=\int_{0}^{1}\left[-\frac{\partial T}{\partial x}+N_{r} Q_{r}\right]_{x=0} d y \\
& Q_{E}=\int_{B}^{1}\left[-\frac{\partial T}{\partial x}+\operatorname{RePruT}+N_{r} Q_{r}\right]_{x=A} d y
\end{aligned}
$$

\section{METHOD OF SOLUTION}

The nonlinear partial differential governing equations, Eqs. (1)-(3), were discretized using a finite difference technique. The first and second derivatives of the diffusive terms were approached by central differences while a second order upwind scheme was used for the convective terms to avoid possible instabilities frequently encountered in mixed convection problems. The integration of Eqs. (1) and (2) was ensured by the Alternating Direction Implicit method (ADI). At each time step, the Poisson equation, Eq. (3), was treated by using the Point Successive Over-Relaxation method (PSOR) with an optimum over-relaxation coefficient equal to 1.88 for the grid adopted in the present study. The set of Eq. (5), representing the radiative heat transfer between the different elementary surfaces of the cavity, was solved by using the Gauss-Seidel method. The numerical code was validated against the results of Akiyama and Chong (1997) obtained in the case of a square cavity differentially heated. Comparisons, made in terms of convective Nusselt numbers, evaluated at the heated wall, showed a fairly good agreement with relative maximum deviations limited to $1.07 \%$ / (1.36\%) for $\varepsilon=0 /$ (1) for $R a$ varying in the range $10^{3} \leq R a \leq 10^{6}$ (Table 1). Other tests of validation were also performed (results not presented) and showed an excellent agreement with results obtained by Ramesh et al. (1999) in terms of temperature profiles along the adiabatic horizontal walls of a differentially heated cavity.

The calculations were performed on a Pentium 4 (Processor: Intel $\times 86$ Family 15 Model 1 Stepping 2$1.6 \mathrm{GHz}$, Memory: $256 \mathrm{MB}$ RAM) with a uniform grid of $81 \times 41$ for both $\mathrm{x}$ and $\mathrm{y}$ directions; grid selected as a reasonable compromise between computational effort and required accuracy. The results obtained with this grid were comparable to those obtained with a finer grid of $121 \times 61$. In fact, the refinement of the grid to $121 \times 61$ generates maximum variations lower than $0.69 \%$ and $1.37 \%$ in terms of $\Psi_{\max }$ and Nu respectively (Table 2). The grid optimization is also made by examining the grid effect on the computational effort in terms of CPU time. It is found that the computational effort is increased by about $65 \%$ by refining the grid of $81 \times 41$ to $121 \times 61$.

\section{RESUlts AND Discussion}

In convective heat transfer problems where the thermal radiation is considered, the Rayleigh number, $R a$, the convection-radiation interaction number, $\mathrm{N}_{\mathrm{r}}$, and the dimensionless reference temperature, $T_{o}=\lambda T_{C}^{\prime} / q^{\prime} H^{\prime}$, appear among the main controlling parameters but these three parameters could not be varied simultaneously. In the present study, the value of the temperature of the external imposed flow was maintained constant at $T_{C}^{\prime}=298.15 \mathrm{~K}$. The fixed value of Rayleigh number $\left(\mathrm{Ra}=5 \times 10^{6}\right)$, retained in this study, induces automatic values of the parameters $\mathrm{N}_{\mathrm{r}}$ and $\mathrm{T}_{\mathrm{o}}$ equal to 2.02 and 0.704 , respectively.

In the following, effects of Reynolds number, $200 \leq \mathrm{Re}$ $\leq 5000$, relative height of the partition, $0 \leq \mathrm{H}_{\mathrm{b}} \leq 0.75$, and walls emissivity, $0 \leq \varepsilon \leq 1$, on fluid flow and heat transfer characteristics are illustrated. The calculations were done by considering air as a working fluid $(\mathrm{Pr}=0.72)$. The aspect ratio, $\mathrm{A}$, the relative height of the openings, $\mathrm{B}$, and the relative position of the baffle from the inlet, $\mathrm{L}_{\mathrm{b}}$, are maintained constants at 2, 1/4 and 1 , respectively.

The range of Re considered in this study corresponds to values of the Richardson number, Ri, varying in the range $[0.28,173.61]$. The variation of $\mathrm{Ri}$ in this range simulates natural convection, mixed convection and forced convection dominating regimes. For weak values of $\mathrm{Ri}$, the forced convection is dominant. For $\mathrm{Ri} \geq$ 173.61, instabilities were observed. In fact, the boundary conditions imposed at the inlet of the cavity become not compatible with the physical nature of the problem when natural convection is largely dominating; a big closed cell is formed on the right of the baffle and prevents the free circulation of the imposed flow characterized by the open lines.

The effect of the relative height of the partition, $\mathrm{H}_{\mathrm{b}}$, on the flow structure and temperature distribution is presented in Figs. 2a-2d for $\mathrm{Re}=250$ and $\varepsilon=0.85$. In the absence of the partition, the streamlines of Fig. 2a show the presence of a big trigonometric cell occupying 
almost the upper part of the cavity, above the open lines of the forced flow. The corresponding isotherms are more tightened at the level of the horizontal heated wall signifying large heat transfer. The presence of a partition with a relative height of $\mathrm{H}_{\mathrm{b}}=0.25$ leads to the formation of a visible clockwise cell in the right part of the partition and to a reduction of the size and intensity of the cell located above the forced flow (Fig. 2b). The corresponding isotherms show that convective heat transfer is decreased in the right region of the partition as a consequence of the deceleration of the fluid flow velocity in this region. A further increase of the relative height of the partition to $\mathrm{H}_{\mathrm{b}}=0.5$ and 0.75 (Figs. 2c-2d) acts in favoring the lower cell (aiding effect of natural convection and forced convection) and reducing the upper one.

Variations, versus Re, of the average Nusselt numbers, resulting from contributions of convection and radiation and the total Nusselt number, evaluated along the heated wall, are presented in Figs. 3a-3c for different values of $\mathrm{H}_{\mathrm{b}}$ and $\varepsilon$. It is seen from Fig. 3a that the convective heat transfer increases by the increase of Re, either with or without radiation effect. This behavior results from the fact that mixed convection is supported principally by the direct interaction between the open lines and the heated surface located, at inlet of the cavity and through the closed cell in the right region of the baffle. For a fixed value of $\mathrm{Re}, \mathrm{Nu}_{\mathrm{cv}}$ decreases generally with the increase of $\varepsilon$ and $\mathrm{H}_{\mathrm{b}}$. The negative effect of the latter is attributed to its contribution in reducing the size and intensity of the left convective cell. The effect of $\mathrm{Re}$ on the radiative heat transfer is presented in Fig. $3 \mathrm{~b}$ for $\varepsilon=1$. It can be deduced from this figure that the effect of radiation is enhanced by increasing both $\mathrm{H}_{\mathrm{b}}$ and Re. This behavior is attributed to the fact that the temperature of the horizontal adiabatic wall and that of the heated one are decreased when the relative height of the partition and the Reynolds number are increased which will lead to a direct interaction between the imposed flow and the upper horizontal adiabatic wall (Figs. 4a-4b). The diminution of the temperature of this wall is more favorable to the radiation heat transfer. More precisely, for $\mathrm{H}_{\mathrm{b}}=1 / 4 /(3 / 4), \mathrm{Nu}_{\mathrm{rd}}$ increases by about $40.86 \%$ / $(28 \%)$ when the value of Re passes from 200 to 5000 . The variations of the total Nusselt number with Re, presented in Fig. 3c, show increasing tendencies of $\mathrm{Nu}$ with $\operatorname{Re}$ and $\varepsilon$ which means that the positive impact of radiation on the radiative Nusselt number is more important than its negative effect on the convective Nusselt number. Also, for a given Re, the evolution of $\mathrm{Nu}$ is not substantially influenced by the relative height of the fin, $\mathrm{H}_{\mathrm{b}}$ since the negative effect of this parameter on $\mathrm{Nu}_{\mathrm{cv}}$ is compensated by its positive effect on $\mathrm{Nu}_{\mathrm{rd}}$.

The contribution of radiation to the total heat transfer through the heated wall of the cavity is quantified by presenting, in Fig. 5, the evolution of the ratio $\mathrm{Nu}_{\mathrm{rd}} / \mathrm{Nu}$ with $\operatorname{Re}$ for $\varepsilon=1$ and various values of $\mathrm{H}_{\mathrm{b}}$. It can be seen that the contribution of radiation increases slightly with Re until a maximum value which depends of $\mathrm{H}_{\mathrm{b}}$. Above this threshold, this contribution decreases by increasing Re; behavior resulting from the fact that $\mathrm{Nu}_{\mathrm{rd}}$ increases with $\mathrm{Re}$ with a rate lower than that of the convective component at high Re (compare Figs. 3a and $3 b$ ). Also, for a given value of $\mathrm{Re}$, the increase of $\mathrm{H}_{b}$ leads obviously to an increase of the radiation contribution. Finally, it must be emphasized that the heat transferred by radiation is, in general, lower than that transferred by convection but the contribution of radiation remains important. Quantitatively, the minimum contribution of the radiative component, observed at $\mathrm{Re}=5000$, is about $38.2 \%$ for $\mathrm{H}_{\mathrm{b}}=0.25$ and $\varepsilon=1$. This means that the contribution of radiation to the overall heat transfer remains non negligible even for a forced flow dominating regime.

For practical applications, it is of great importance to know the impact of the governing parameters on mean and maximum temperatures of the fluid inside the cavity. The mean temperature was obtained from the arithmetic mean temperatures of the inner nodes of the domain. Thus, the variations of these quantities with $\mathrm{Re}$, are presented in Figs. $6 \mathrm{a}-6 \mathrm{~b}$ for $\mathrm{Ra}=5 \times 10^{6}$ and different values of $\mathrm{H}_{b}$ and $\varepsilon$. The evolution of the maximum temperature, $\mathrm{T}_{\max }$, reported in Fig. 6a, and generally located on the heated wall, shows a decrease of this parameter by increasing $\varepsilon$ or Re but its variation remains insensitive to $\mathrm{H}_{\mathrm{b}}$. This behaviour could be explained by the fact that the overheating phenomenon is avoided by increasing $\mathrm{Re}$ and $\varepsilon$. Indeed, the imposed incoming flow contributes to refresh the upper adiabatic wall; that leads to a great local temperature difference between this wall and the lower heated one. This result enhances the radiative heat flux released by the heated wall; which decreases its local temperature. It is seen from Fig. 6b that $\bar{T}$ decreases by increasing $\varepsilon$ and Re while increases with $\mathrm{H}_{\mathrm{b}}$. In fact, the increase of the overall heat transfer with both $\varepsilon$ and Re (Fig. 3c), contributes to a better cooling within the cavity.

The total quantity of heat dissipated by the heated wall is transferred through the left wall and the exit of the cavity; $\mathrm{Q}_{\mathrm{L}}$ and $\mathrm{Q}_{\mathrm{E}}$ being these quantities, respectively. The quantification of the relative amount of heat, dissipated by each of these two issues, is presented in Fig. 7 in terms of variations of the ratio $\mathrm{Q}_{\mathrm{E}} / \mathrm{Q}_{\mathrm{L}}$ versus Re for different values of $\varepsilon$ and $\mathrm{H}_{\mathrm{b}}$. It is observed that in the absence of radiation $(\varepsilon=0)$, the heat generated by the thermally active bottom wall is mainly dissipated through the exit since the mixed convection plays an important role, supported by the interaction between the open lines and the heated surface; directly in the left part of the baffle and through the closed cell in the right part of the baffle. The consideration of the effect of thermal radiation leads to favour the heat dissipated through the cold surface to the detriment of the component leaving the cavity through the exit. Also, in the absence of radiation $(\varepsilon=0), \mathrm{Q}_{\mathrm{E}} / \mathrm{Q}_{\mathrm{L}}$ increases with Re but its variation with $\mathrm{H}_{\mathrm{b}}$ is marked by two tendencies; increase/decrease for weak/high values of Re. For the maximum value of the emissivity $(\varepsilon=1)$, $\mathrm{Q}_{\mathrm{E}} / \mathrm{Q}_{\mathrm{L}}$ is favoured by the increase of $\mathrm{H}_{\mathrm{b}}$ and $\mathrm{Re}$.

\section{CONCLUDING REMARKS}

Coupled mixed convection and thermal radiation inside a partitioned ventilated cavity has been studied numerically. Results of the study show that the adiabatic partition affects drastically the flow structure and temperature distribution inside the cavity by promoting the formation of a large clockwise cell in its 
right part. It is found that the relative height of the partition, $\mathrm{H}_{\mathrm{b}}$, contributes to increase / (decrease) the radiative / (convective) heat transfer component at the level of the heated wall. The radiation effect leads to a reduction of the convective Nusselt number component (result consistent with previous findings in the literature) but the Reynolds number, Re, supports both radiative and convective heat transfer modes. The parameters $\operatorname{Re}$ and $\varepsilon$ are seen to have a positive effect on the total heat transfer. Generally, the contribution of radiation remains not negligible even if the heat released by radiation is lower than that dissipated by convection. The cooling process of the cavity, characterized by a decrease of mean and maximum temperatures of the fluid, is ensured by increasing both $\operatorname{Re}$ and $\varepsilon$ and decreasing $\mathrm{H}_{\mathrm{b}}$. Finally, it is found that the main part of heat released by the heated wall, is dissipated through the exit while varying the controlling parameters in their respective ranges and the heat dissipated through the left cold wall is supported by increasing $\varepsilon$ and decreasing of Re.

\section{REFERENCES}

Akiyama, M. and Q.P. Chong (1997). Numerical analysis of natural convection with surface radiation in a square enclosure. Numer Heat Transfer, Part A 31, 419-433.

Bahlaoui, A., A. Raji and M. Hasnaoui (2004). Coupling between mixed convection and radiation in an inclined channel locally heated. J Mech Eng $55,45-57$.

Bahlaoui, A., A. Raji and M. Hasnaoui (2005). Multiple steady state solutions resulting from coupling between mixed convection and radiation in an inclined channel. Heat Mass Transfer 41, 899-908.

Bhoite, M.T., G.S.V.L. Narasimham and M.V. Krishna Murthy (2005). Mixed convection in a shallow enclosure with a series of heat generating components. Int J Thermal Sciences 44, 121-135.

Deng, Q.H., J. Zhou, C. Mei and Y.M. Shen (2004). Fluid, heat and contaminant transport structures of laminar double-diffusive mixed convection in a two-dimensional ventilated enclosure. Int $\mathrm{J}$ Heat Mass Transfer 47, 5257-5269.

Hottel, H.C. and A.F. Saroffim (1967). Radiative heat transfer. McGraw-Hill, New York.

How, S.P. and T.H. Hsu (1998). Transient mixed convection in a partially divided enclosure. Comput Math Appl 36, 95-115.

Hsu, T.H., P.T. Hsu and S.P. How (1997). Mixed convection in a partially divided rectangular enclosure. Numer Heat Transfer, Part A 31, 655683.

Lennie, T.B., D.P. McKenzie, D.R. Moore and N.O. Weiss (1998). The breakdown of steady convection. J Fluid Mech 188, 47-85.
Manca, O., S. Nardini, K. Khanafer and K. Vafai (2003). Effect of heated wall position on mixed convection in a channel with an open cavity. Numer Heat Transfer, Part A 43, 259-282.

Mousavi, S.S. and K. Hooman (2006). Heat and fluid flow in entrance region of a channel with staggered baffles. Energy Conversion and Management 47, 2011-2019.

Najam, M., M. El Alami and A. Oubarra (2004). Heat transfer in a " $T$ ", form cavity with heated rectangular blocks submitted to a vertical jet: the block gap effect on multiple solutions. Energy Conversion and Management 45, 113-125.

Papanicolaou, E. and Y. Jaluria (1990). Mixed convection from an isolated heat source in a rectangular enclosure. Numer Heat Transfer, Part A $18,427-461$.

Papanicolaou, E. and Y. Jaluria (1993). Mixed convection from a localized heat source in a cavity with conducting walls: A numerical study. Numer Heat Transfer, Part A 23, 463-484.

Raji, A. and M. Hasnaoui (1998a). Mixed convection heat transfer in a rectangular cavity ventilated and heated from the side. Numer Heat Transfer, Part A $33,533-548$.

Raji, A. and M. Hasnaoui (1998b). Corrélations en convection mixte dans des cavités ventilées. Revue Générale de Thermique 37, 874-884.

Raji, A. and M. Hasnaoui (2000). Mixed convection heat transfer in ventilated cavities with opposing and assisting flows. Eng Comput: Int J ComputerAided Eng Software 17, 556-572.

Raji, A. and M. Hasnaoui (2001). Combined mixed convection and radiation in ventilated cavities. Eng Comput: Int J Computer-Aided Eng Software 18, 922-949.

Ramesh, N., C. Balaji and S.P. Venkateshan (1999). Effect of boundary conditions on natural convection in an enclosure. Int J Trans Phenomena 1, 205-214.

Saha, S., G. Saha, M. Ali and M. Quamrul Islam (2006). Combined free and forced convection inside a two-dimensional multiple ventilated rectangular enclosure. ARPN J Eng Appl Sciences 1(3), 23-35.

Singh, S. and M.A.R. Sharif (2003). Mixed convective cooling of a rectangular cavity with inlet and exit openings on differentially heated side walls. Numer Heat Transfer, Part A 44, 233-253. 
A. Bahlaoui et al. / JAFM, Vol. 4, No. 1, pp. 89-96, 2011.

Table 1 Effect of $\mathrm{Ra}$ and $\varepsilon$ on the mean convective Nusselt number, $\mathrm{Nu}_{\mathrm{cv}}$, evaluated on the heating wall of a square cavity for $\mathrm{T}_{\mathrm{H}}^{\prime}=298.5 \mathrm{~K}$ and $\mathrm{T}_{\mathrm{C}}^{\prime}=288.5 \mathrm{~K}$.

\begin{tabular}{l|cccc|cccc}
\hline & \multicolumn{4}{|c|}{$\varepsilon=\mathbf{0}$} & \multicolumn{4}{c}{$\varepsilon=1$} \\
\hline Ra & $\mathbf{1 0}^{\mathbf{3}}$ & $\mathbf{1 0}^{\mathbf{4}}$ & $\mathbf{1 0}^{\mathbf{5}}$ & $\mathbf{1 0}^{\mathbf{6}}$ & $\mathbf{1 0}^{\mathbf{3}}$ & $\mathbf{1 0}^{\mathbf{4}}$ & $\mathbf{1 0}^{\mathbf{5}}$ & $\mathbf{1 0}^{\mathbf{6}}$ \\
Present work & 1.118 & 2.257 & 4.627 & 9.475 & 1.250 & 2.242 & 4.192 & 8.100 \\
Akiyama and Chong (1997) & 1.125 & 2.250 & 4.625 & 9.375 & 1.250 & 2.250 & 4.250 & 8.125 \\
\hline
\end{tabular}

Table 2 Grids effect on the obtained results for $\mathrm{Ra}=5 \times 10^{6}\left(\mathrm{~N}_{\mathrm{r}}=2.02\right), \mathrm{H}_{\mathrm{b}}=1 / 2, \mathrm{~L}_{\mathrm{b}}=1$ and different values of $\operatorname{Re}$ and $\varepsilon$.

\begin{tabular}{|c|c|c|c|c|c|c|c|c|}
\hline \multirow[b]{3}{*}{ Grids } & \multicolumn{4}{|c|}{$\operatorname{Re}=200$} & \multicolumn{4}{|c|}{$\operatorname{Re}=300$} \\
\hline & \multicolumn{2}{|c|}{$\varepsilon=0.15$} & \multicolumn{2}{|c|}{$\varepsilon=0.85$} & \multicolumn{2}{|c|}{$\varepsilon=0.15$} & \multicolumn{2}{|c|}{$\varepsilon=0.85$} \\
\hline & $\Psi_{\max }$ & $\mathbf{N u}_{\mathrm{H}}$ & $\Psi_{\max }$ & $\mathbf{N u}_{\mathbf{H}}$ & $\Psi_{\max }$ & $\mathbf{N u}_{\mathbf{H}}$ & $\Psi_{\max }$ & $\mathbf{N u}_{H}$ \\
\hline $81 \times 41$ & 0.290 & 10.292 & 0.281 & 13.605 & 0.270 & 10.634 & 0.267 & 14.215 \\
\hline $121 \times 61$ & 0.288 & 10.427 & 0.280 & 13.780 & 0.271 & 10.780 & 0.268 & 14.400 \\
\hline
\end{tabular}
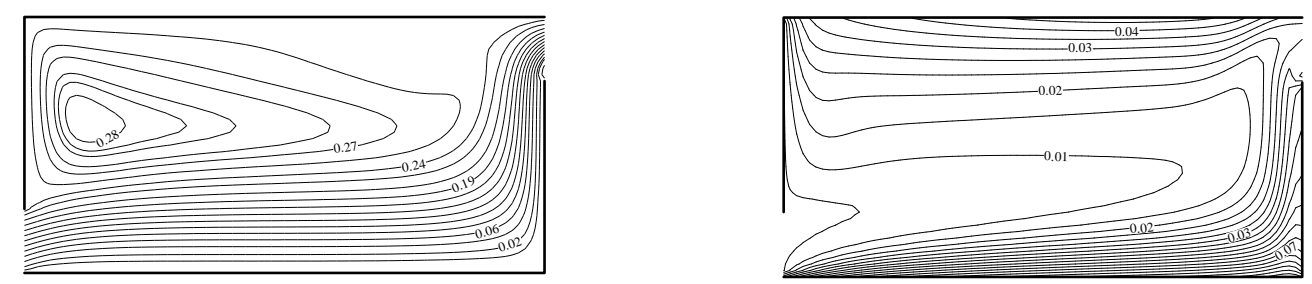

a) $\mathrm{H}_{\mathrm{b}}=0\left(\Psi_{\min }=-0.04, \Psi_{\max }=0.29\right)$
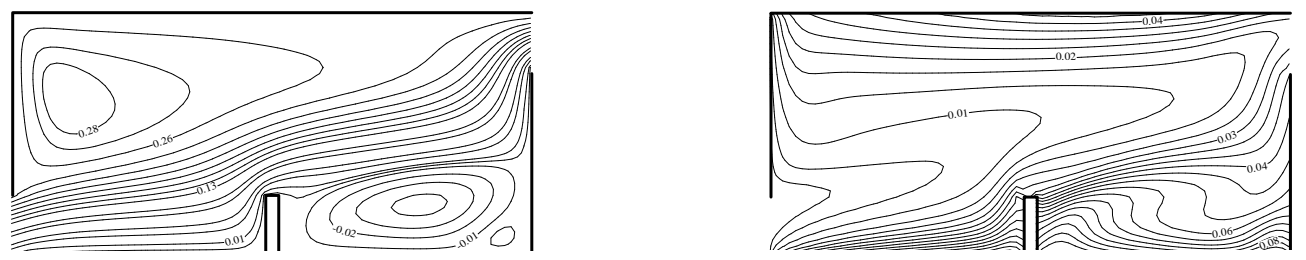

b) $\mathrm{H}_{\mathrm{b}}=0.25\left(\Psi_{\min }=-0.06, \Psi_{\max }=0.29\right)$
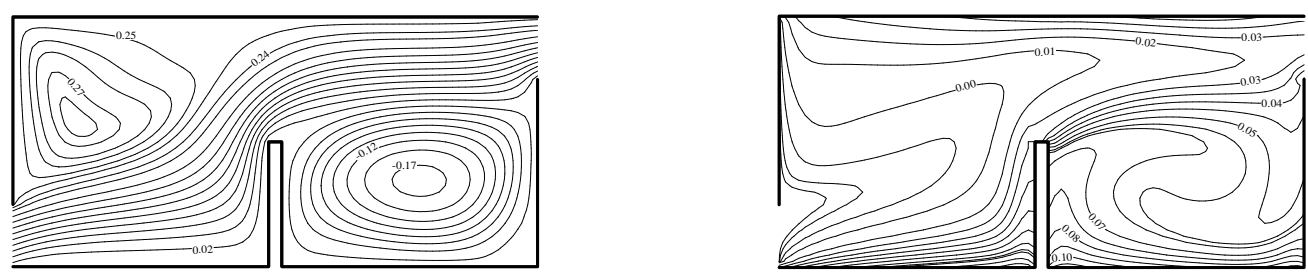

c) $\mathrm{H}_{\mathrm{b}}=0.5\left(\Psi_{\min }=-0.17, \Psi_{\max }=0.27\right)$
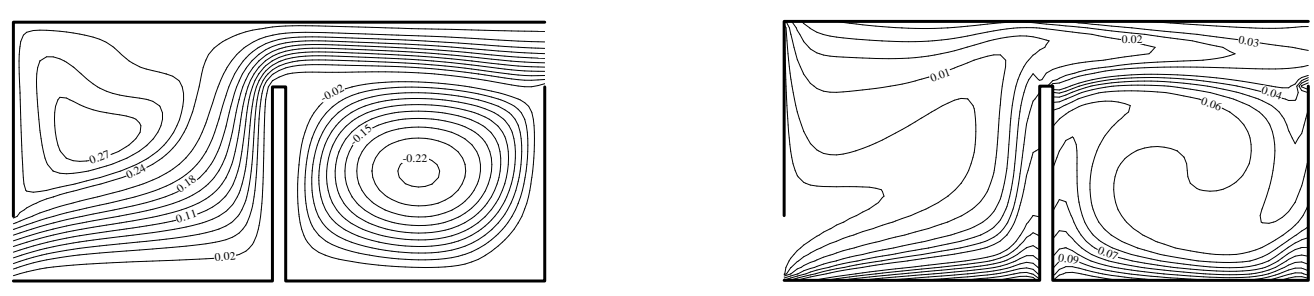

d) $\mathrm{H}_{\mathrm{b}}=0.75\left(\Psi_{\min }=-0.22, \Psi_{\max }=0.27\right)$

Fig. 2. Streamlines and isotherms obtained for $\mathrm{Re}=250, \mathrm{Ra}=5 \times 10^{6}, \varepsilon=0.85$ and various values of $\mathrm{H}_{\mathrm{b}}$ : a) $\left.\left.\mathrm{H}_{\mathrm{b}}=0\left(\Psi_{\min }=-0.04, \Psi_{\max }=0.29\right) ; \mathrm{b}\right) \mathrm{H}_{\mathrm{b}}=0.25\left(\Psi_{\min }=-0.06, \Psi_{\max }=0.29\right) ; \mathrm{c}\right) \mathrm{H}_{\mathrm{b}}=0.5\left(\Psi_{\min }=\right.$ $\left.-0.17, \Psi_{\max }=0.27\right)$ and d) $\mathrm{H}_{\mathrm{b}}=0.75\left(\Psi_{\min }=-0.22, \Psi_{\max }=0.27\right)$. 

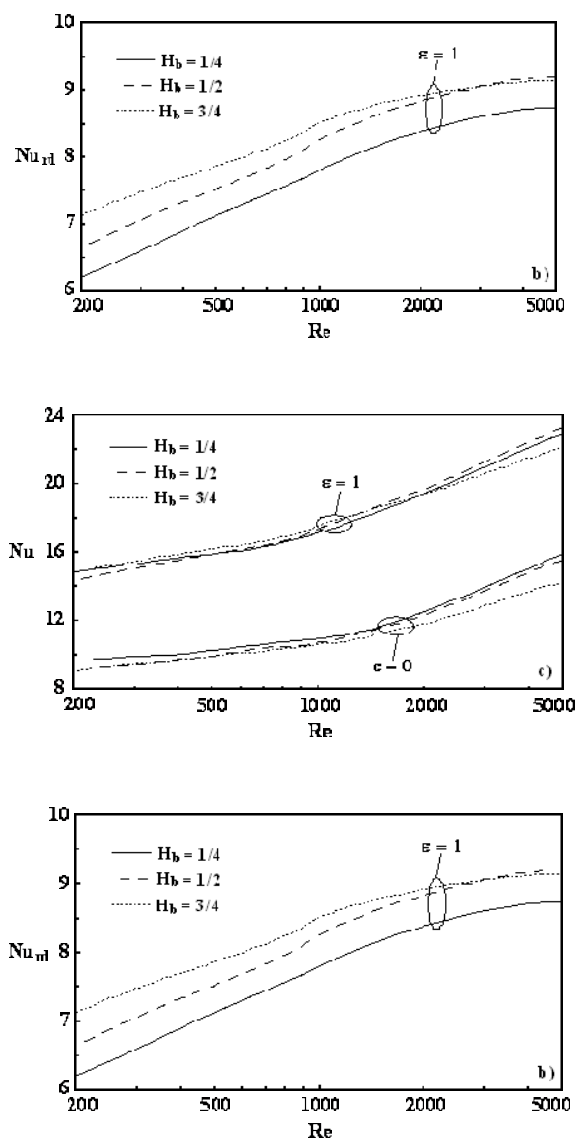

Fig. 3. Variations, with Re, of the average Nusselt numbers on the heated wall for $\mathrm{Ra}=5 \times 10^{6}$ and various values of $\varepsilon$ and $\mathrm{H}_{\mathrm{b}}$ : a) $\mathrm{Nu}_{\mathrm{cv}}$; b) $\mathrm{Nu}_{\mathrm{rd}}$ and c) $\mathrm{Nu}$.
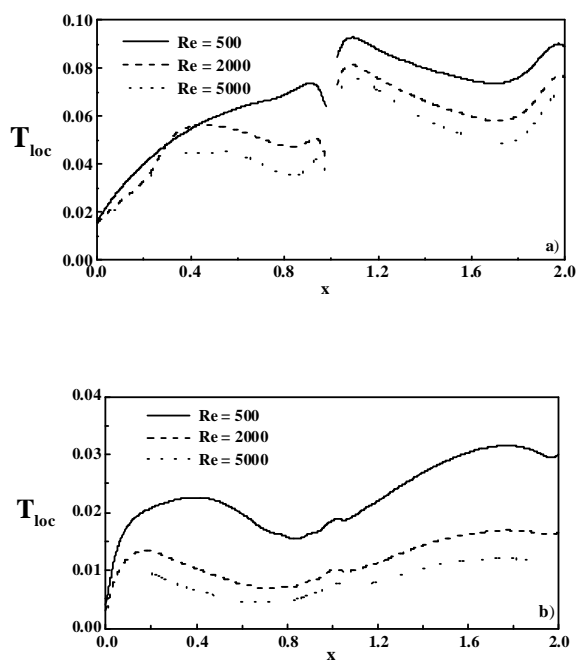

Fig. 4. Variation of the local temperature along the horizontal walls for $\mathrm{Ra}=5 \times 10^{6}, \mathrm{H}_{\mathrm{b}}=3 / 4, \varepsilon=$ 1 and various values of Re: a) lower heated wall and b) upper adiabatic wall.

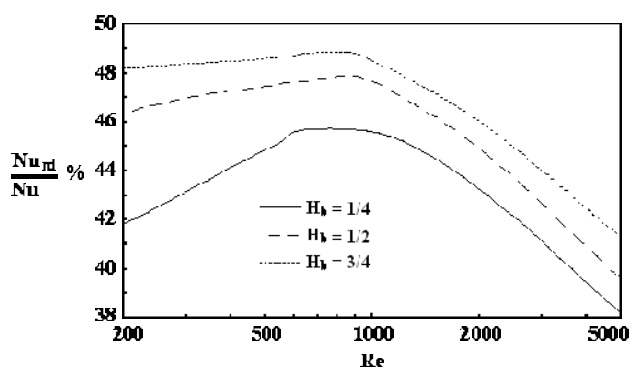

Fig. 5. Contribution of radiation evaluated at the heated wall, as a function of $\mathrm{Re}$, to the overall heat transfer for $\mathrm{Ra}=5 \times 10^{6}, \varepsilon=1$ and various values of $\mathrm{H}_{\mathrm{b}}$.
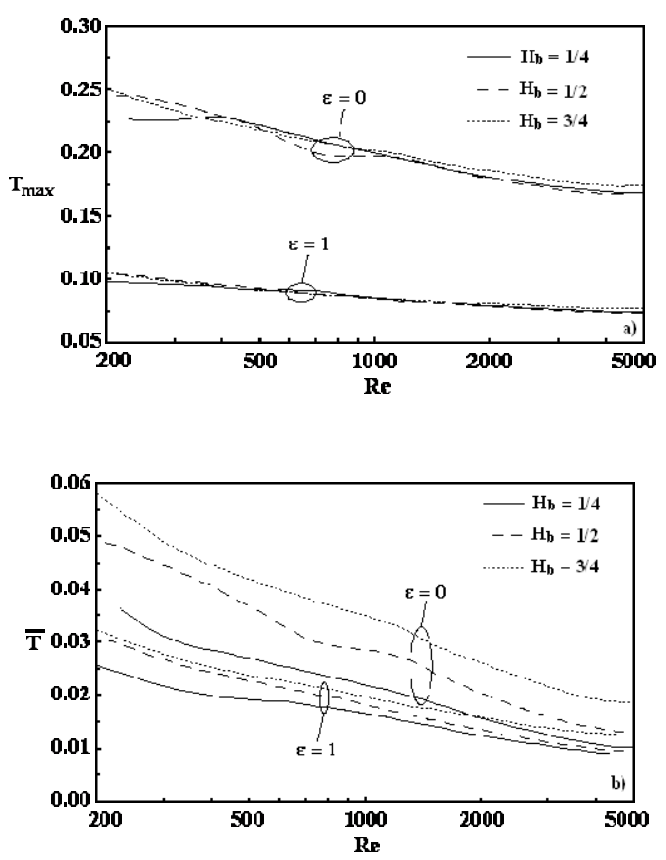

Fig. 6. Variations, with $\mathrm{Re}$, of the temperature for, $\mathrm{Ra}=5 \times 10^{6}$ and various values of $\varepsilon$ and $\mathrm{H}_{\mathrm{b}}$ : a) maximum temperature $\mathrm{T}_{\max }$ and $\mathrm{b}$ ) mean temperature $\overline{\mathrm{T}}$.

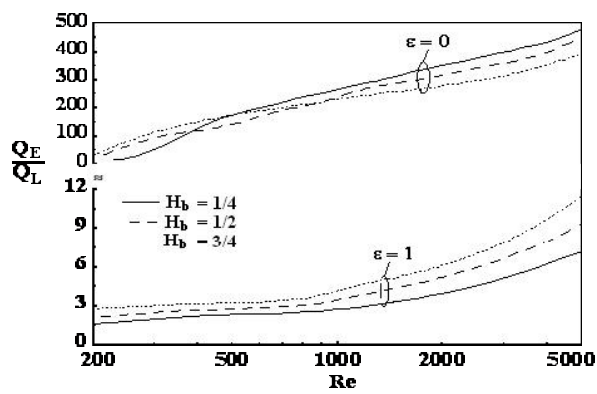

Fig. 7. Variations, with $\mathrm{Re}$, of the ratio $\mathrm{Q}_{\mathrm{E}} / \mathrm{Q}_{\mathrm{L}}$ for $\mathrm{Ra}=5 \times 10^{6}$ and various values of $\varepsilon$ and $\mathrm{H}$ 